\title{
Research-Based Design and Green Buildings: Interdisciplinary Collaboration Between Students, Faculty and Practitioners
}

\author{
KALINA VANDER POEL \\ Portland State University \\ COREY GRIFFIN \\ Portland State University
}

Over the past five years, faculty in the School of Architecture at Portland State University have been awarded four grants totaling over $\$ 1,000,000$ to transform green building education with an emphasis on interdisciplinary experiences, researchbased design and collaboration with practice. This paper highlights the progress and lessons learned from three interrelated programs: the Researchbased Design Initiative, the Building Science Lab to Advance Teaching and the Green Building Scholars Program. Issues discussed include barriers to conducting collaborative green building research between the academy and practice, the challenges of interdisciplinary coursework, and how these programs could be a model for other universities.

\section{INTRODUCTION}

Buildings consume 41 percent of the primary energy and are responsible for 40 percent of carbon dioxide emissions in the US. ${ }^{1}$ These numbers exclude the significant environmental impact of manufacturing, transporting, installing, maintaining and eventually demolishing materials used in building construction. ${ }^{2}$ While every other sector has been reducing energy use over the last 30 years, commercial buildings have increased their energy intensity (energy use per square foot) by over $8 \%$. It is well documented that deficiencies in building performance are ubiquitous, and if addressed nationally in the US could contribute to over $\$ 18$ billion in savings annually. ${ }^{3}$ Thus, to mitigate climate change, there should be no higher priority than ensuring that buildings are created, adapted and retrofit to minimize energy use, resource consumption, and cost. One primary approach to high-performance or green building design and construction is to utilize rules of thumb and rating systems that have been found to provide no guarantee in reducing actual energy consumption below current averages. ${ }^{4}$ These methods alone are no longer sufficient as society demands net zero energy and carbon buildings - not just incremental improvements in building performance.
Instead, design decisions must be based on a combination of robust scientific knowledge and applied research. The greatest opportunity for research is in academia where there are resources available to test pressing questions related to the design and engineering of green buildings.

Interdisciplinary collaboration between engineers and architects during the design and construction of a building is also critical to the reduction of energy use and the delivery of green buildings. ${ }^{5}$ However, there is little if any interaction between architecture and engineering students during their education, and there are a number of barriers to interdisciplinary courses and programs in academia. ${ }^{6}$ Green building "charrettes," collaborative meetings of stakeholders early in the design process to discuss engineering and design strategies to reduce resource use, are common in professional practice. However, the efficacy of these charrettes is limited by numerous barriers between participants of different disciplines, including disparate value systems and terminology. ${ }^{7}$ As members of the building industry are highly influenced by their early training, one way to overcome these barriers is by offering opportunities for engineering and architecture students to take building science courses in other disciplines and have meaningful and substantive experiences together during their education. This will allow individuals to better understand the language, motivations and biases of each discipline in order to become more effective collaborators in the future. The Royal Academy of Engineering recently released a report arguing for the urgent transformation of engineering education to emphasize multi-disciplinary research in building design, engineering, energy and carbon efficiency and the need to recruit the best engineers of each generation to reduce the environmental impact of buildings. ${ }^{8}$

To address both of these issues, Portland State University's (PSU) School of Architecture has been awarded four grants totaling over $\$ 1,000,000$ to generate translational building science research in collaboration with local architecture and engineering firms and promote interdisciplinary educational efforts. The result is a combination of highly specified interventions and course development that ensure students will be effective researchers, collaborators and leaders when they are part of multidisciplinary teams in practice. 


\section{EXISTING MODELS}

There are several models practiced throughout the US for aligning academic architectural research with the needs of practice. Evidence based design is "the process of basing decisions about the built environment on credible research to achieve the best possible outcomes." 9 With particular emphasis on human health metrics, evidence based design aligns itself with the healthcare industry. Evidence based design research can be found in interdisciplinary university centers such as the Center for Health Systems and Design at Texas A\&M and the PhD Concentration in Evidence-Based Design in the School of Architecture at Georgia Tech.

To distinguish itself from the established field of evidence-based design, research-based design is a generalized term used to describe research focused on reducing the environmental impact of buildings. Research-based design "uses quantitative data collected from existing buildings, generated through rapid prototyping and testing, or simulated using parametric and genetic computer modeling to reduce resource consumption through improved design."10 In academia, research-based design is typically deployed in one of three ways. Research-based design can be (1) used to promote research skills relevant to practice in academia, (2) generated in university laboratories supported by professional consortium, and (3) found when the academy acts as a consultant. ${ }^{11}$ While each of these are successful in generating research-based design, there exists a need for more direct application of research into architectural practice. ${ }^{12}$ Additionally, these methods provide few opportunities for students to collaborate in an interdisciplinary environment.

Within the discipline of medicine, there is a successful relationship between research and practice. Known as translational research, results from laboratory research and tools from academia are applied directly to practice. Implementation of translational research is argued to improve building science education and practice..$^{13}$ It has the potential to increase adoption of new software, tools and strategies in the building industry, break down disciplinary barriers, and practicing professionals have the ability to influence research agendas in academia. ${ }^{14}$

Three models have been proposed for translational research in regards to architectural education and practice. These models include: (1) practice embedded in the academy (2) the academy embedded in practice and (3) collaboration..$^{15}$ These models (or a combination of these models) are currently implemented in the academy with examples found at RMI's Center for Architecture Science and Ecology, University of Minnesota's MS in Research Practices, and Portland State University's Research-based Design Initiative. This paper focuses on the advantages, challenges, and evolution of the Researchbased Design Initiative (RBDI) to utilize translational research and interdisciplinary collaboration as a means to encourage better building performance.

\section{RESEARCH-BASED DESIGN INITIATIVE (RBDI)}

Initially funded through an National Council of Architectural Registration Board (NCARB) grant with subsequent funding through a
$\$ 100,000$ five-year grant from the Oregon Community Foundation and $\$ 40,000$ in contributions from participating firms, Professors Corey Griffin and Sergio Palleroni transformed two graduate level building science and technology courses from lecture and case study based seminars into practice and research oriented courses. The goals of the RBDI set out in the original NCARB grant proposal are as follows: (1) Expose architecture students to various models for multidisciplinary collaboration by embedding them in professional design teams. (2) Provide architecture students with the opportunity to lead an interdisciplinary team of peers. (3) Generate original sustainability research to assist practice with pressing needs and improve the public health and welfare.

The faculty instructors of these courses, continued to ensure students are given the content required to meet National Architectural Accreditation Board (NAAB) and departmental standards, the outcomes and deliverables of the course shifted to focus on multidisciplinary collaboration and original sustainability research relevant to practice. Advanced Building Structures, an elective seminar, was the first pilot for this new methodology in Winter 2012. Advanced Building Technology, a required course for students entering the Masters of Architecture program, and Advanced Building Structures (later renamed - Building Science Research Methods) expanded these efforts in Fall 2012 and Winter 2013.

Currently, the RBDI is a series of on-going, graduate level seminars that revolve around two primary activities: (1) architecture and engineering students conduct building science research of relevance to a project in an architecture firm and (2) students are embedded in project teams where they attend all interdisciplinary meetings for the course of a term to witness and document interdisciplinary collaboration. Students now also have assigned space in the firm's office in improve collaboration with the firms. In this unique way, students become contributing members of a design team and building science experts on issues relevant to current practice. For the architecture firms involved, working with universities allows practicing architects the ability to utilize a deeper level of research expertise in the design process and access resources not typically available in practice. Academic terms conclude with research symposiums where students present their work to representatives from all of the participating firms, creating a dialog around pressing building science issues with students, faculty and practitioners.

\section{ROLE OF FACULTY, FIRMS, AND STUDENTS}

Imperative to the success of the RBDI is the collaboration of each party involved (faculty, firms, and students). Each party has dedicated responsibilities, roles, and active relationship with the other parties (figure 1). Faculty are responsible for general coordination including the setup and execution of the initiative. Faculty meet with practitioners before the beginning of the academic term in order to elicit feedback on past projects and suggestions for research projects. At the beginning of the term, faculty select which students are to be assigned to which research project, taking student preference, skills, and opportunities for interdisciplinary collaboration into account. 


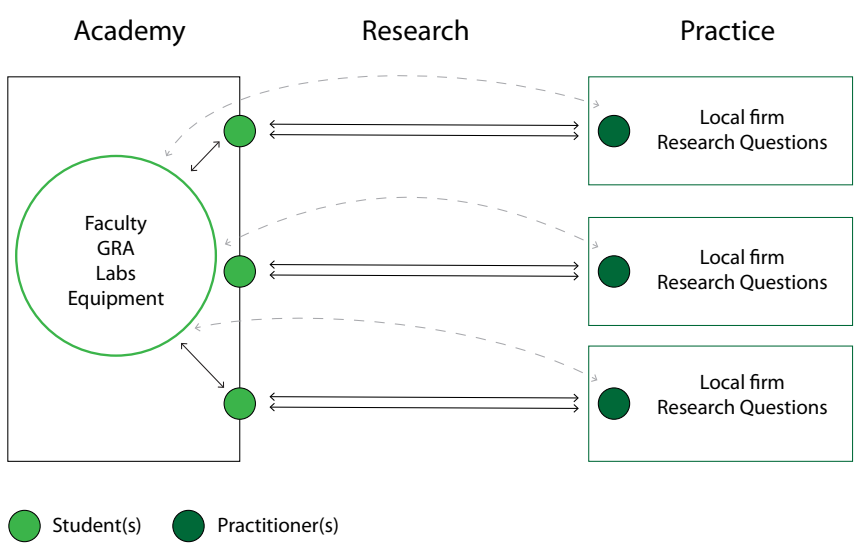

Figure 1: Research Based Design Initiative Organizational Diagram

Once the term begins, faculty assist students by providing resources such as access to software and lab equipment on campus as well as feedback on the research through individual meetings and class assignments.

Firms are responsible for proposing projects and providing assistance to students. A practitioner or group of practitioners at each firm identify research projects and topics that can be related to a project under design or are not depending on the timing of the academic term and project schedules. During the term firm representatives are responsible for meeting with the student(s) regularly and ensure they are included in all multidisciplinary meetings and witness to other forms of interdisciplinary communication (e- mails, conference calls, etc.).

During the research project, architecture students work as part of an interdisciplinary team of peers when possible and generate original sustainability research relevant to the firms and project team of which they are a part. Students are responsible for the integrity of the research and document progress in the form of weekly memos. Weekly memos serve two functions. They document collaboration efforts and current state of the research project, and memos create a record students can use to generate "timelines" presented at the end of the term with their research. Both the memos and timelines are used by faculty and firms when evaluating research projects.

\section{RESULTS OF RESEARCH}

To date, research engendered from the RBDI can be categorized into three types and five topics. The three types of research include simulation, post occupancy analysis/field research, and precedent research. Simulation enables rapid testing of design iterations, and students with simulation research projects regularly present not one, but many different iterations of the design project. These iterations are largely visual, including quantifiable metrics on simulated performance through a specified software.

Post occupancy analysis/field research include point in time and/ or extended data collection of the built environment for validation of past design decisions. Building science tools used to collect data include infrared thermographers, time lapse cameras, sound meters, light meters, occupancy sensors, temperature and humidity sensors. Post occupancy research is not only useful for validation but also applicable to future design projects of the firm. Precedent research involves literature and case study research on topics and cutting edge technologies that the firm has yet to have significant experience with.

Research topics include building envelopes, structural systems, daylighting/solar gain, ventilation (natural and displacement), and building retrofits (figure 2). Topics vary from year to year, term to term, with envelopes and daylighting/solar gain being most common. Firms can gravitate towards one research topic. For example, a firm may be particularly interested in studying daylighting regardless of project, research type, or student group.

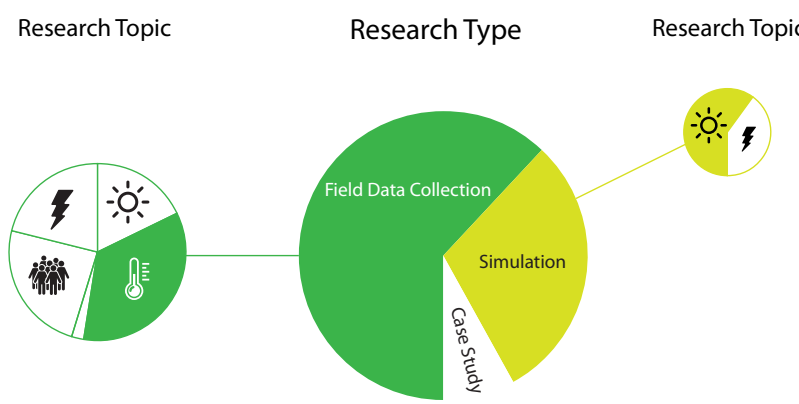

Figure 2: Research Breakdown 2015-2016

\section{STAKEHOLDER FEEDBACK FOR RBDI}

Feedback about the RBDI was gathered through a combination of surveys and in-person discussions. Surveys are distributed to firms and students on an annual basis and include closed-ended and openended questions. In-person discussions with the practitioners involved happen before, during, and at the conclusion of each academic term to provide additional feedback. With regards to the three goals of the RBDI, the general opinion is favorable and the majority of individuals felt the goals of (1) collaboration, (2) interdisciplinary groups, and (3) translational research had been well met (figure 3). Additionally, the RBDI has regularly been appreciated for the dual benefit it has for firms and students. In his feedback, one practitioner summarized the unique value of this collaboration: "Throughout my involvement with the PSU RBDI, I have been struck by the unique opportunities it offers to students to directly engage in active projects and offer actionable feedback that can impact the final project designs. For firms the RBDI provides access to engaged and motivated students who can dig into issues that the design team may not have the personnel resources to fully explore. It also is an opportunity for firms that ask questions that may be tangential to project completion (new tools, new process) but can inform later work."

While the goals of the RBDI were met, there has been and still is room for improvement. "Interdisciplinary collaboration" has the weakest indication of success. This primarily stems from the challenge of recruiting engineering students to take architecture coursework. 

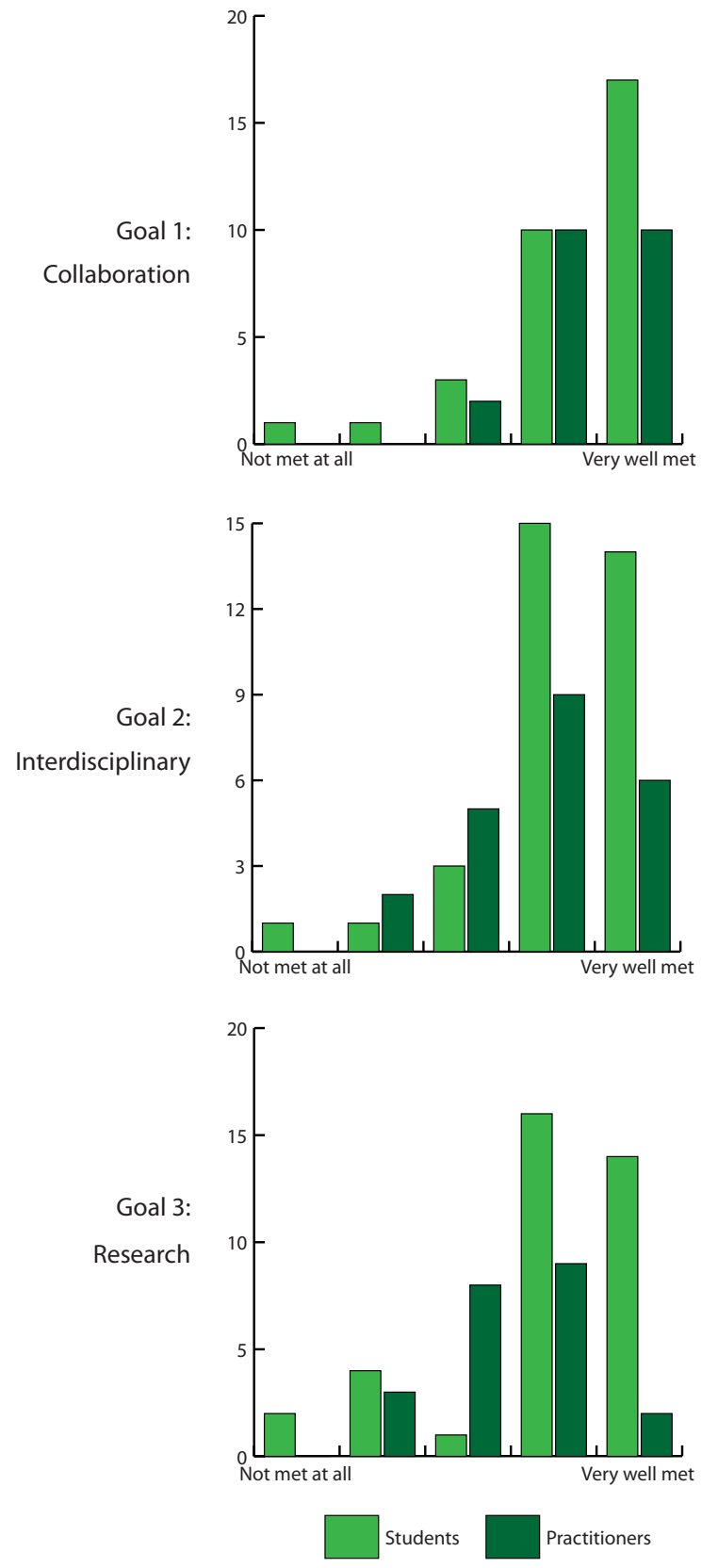

Figure 3: Feedback on Goals met for Research Based Design Initiative

Given the rigorous demands of architecture and engineering degree programs, there is little space or time for students to take classes they do not count toward their degrees. As Portland State University is an "access" university, it charges tuition by the credit hour providing additional financial barriers for students to take elective coursework. To overcome these barriers, faculty in Architecture, Civil Engineering and Mechanical Engineering at PSU applied for and received a grant from the National Science Foundation to encourage students at all levels to study building science. This program will be discussed in more detail later in the paper.

Additionally, the quality of the student research was not always as high as desired. This is due primarily to the students' lack of previous research experiences and building science knowledge. The graduate seminars used in the RBDI have no prerequisites; consequently many students are simultaneously learning basic concepts and applying them to a research project simultaneously. Firms and students have found the research could end up being an opportunity to learn how to conduct building science research rather than provide a research result that significantly impacted design decisions in practice.

\section{OUTCOMES OF RESEARCH BASED DESIGN INITIATIVE}

There are a number of positive outcomes and lessons learned from these seminars over the past five years. As the first course in the RBDI is required, all graduate architecture students at Portland State University are trained with research skills applicable to advancing professional practice. Each graduate student also acquires experience working with a local architecture firm. Firms have the benefit of students conducting research for their office. The semi-annual symposium is particularly rewarding as research is shared between firms and larger questions about advancing the role of research in practice are regularly discussed. A number of students have been hired by the firms they have worked with to continue their research in a full time internship over the summer as well as offered full-time positions once they graduated.

A number of drawbacks hinder the progress and ease of implementation for the RBDI. Drawbacks include academic term influencing scope of research project, limited time and resources for faculty, limited availability of resources for students, and quality of research. Drawbacks such as length of academic term can not be helped. Other drawbacks, such as time and resources, can be dramatically reduced with additional funding to increase availability, dedicated staff support, and additional resources. The most problematic drawback is the quality of research. Overarchingly, both firms and students agree research skills are not as high as they would like. To address the lack of research skills, Professor Griffin received a grant to incorporate building science research experiences in undergraduate coursework and develop a new teaching lab, Building Science Lab to Advance Teaching (BUILT).

\section{BUILDING SCIENCE LAB TO ADVANCE TEACHING (BUILT)}

Based on the outcomes of the RBDI, Professor Griffin recognized the need for a new lab to be located within the School of Architecture that was dedicated to educating students on building science with particular emphasis on building science research skills. In late 2014, Professor Griffin was awarded a $\$ 300,000$ W.M. Keck Foundation Undergraduate Research grant to create the Building Science Lab to Advance Teaching (BUILT). BUILT promotes early development of building science research skills in higher education by exposing students to hands on, collaborative building science research activities. Geared towards undergraduate students, BUILT provides students and faculty members resources including a physical lab with space to host seminars, a tool lending library, and dedicated staff (figure 4). As a teaching lab, BUILT is equipped with computers, sensors, designsimulation software and fabrication tools for the research and analysis of existing building performance and testing of proposed designs. In 
addition, the lab has a large conference table where students and faculty can hold either impromptu or planned meetings, classes and events. BUILT staff hold regularly scheduled open hours for the lab. During those times, students can come ask questions, receive one-onone training, and check out equipment.

At BUILT there are over 250 pieces of equipment available for student checkout. BUILT's tool lending library is comprised of building science tools that collect point-in-time and/or prolonged building performance metrics including light, temperature, wind, sound, etc. As students may not have prior knowledge of tool use, tools are specifically selected for their ease of use in observation, collection, and retrieval of data. For example, BUILT makes use of the Vernier LabQuest2 hardware that is designed for K-12 as well as university science lab settings. It consists of touch screen base station and external sensors that are plug and play. The LabQuest is both a tool for taking in situ measurements as well as a data logger that can easily export data by e-mail. In addition to tools, BUILT has an extensive simulation software library students can "check out" through reservation of 1 of 4 lab computers.

BUILT promotes new teaching models for building science education by embraces active learning exercises as a means to introduce building science concepts and research methods into traditional classroom

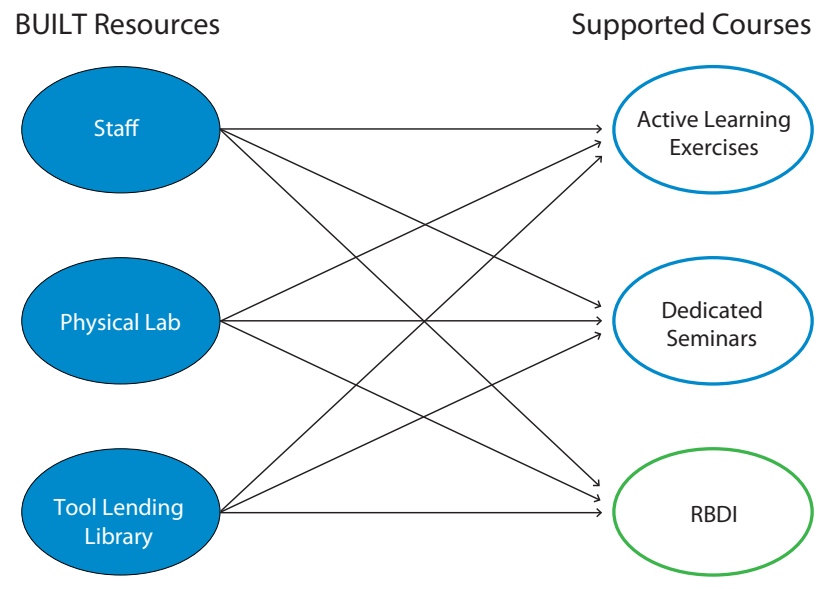

Figure 4: BUILT resources and support diagram

environments. BUILT supports these active learning exercises by providing resources such as a building science knowledge base, the development of handouts and worksheets, specifying appropriate tools, assist with tool check-out and use, and deliver in-class lectures on building science. Additionally, BUILT supports dedicated building science courses. These courses have significant research components and introduce students to new building science tools and methods. While BUILT is tailored towards undergraduate student body, BUILT's staff, lab, and tools are available to RBDI students, faculty, and firms. By supporting a variety of courses, student-led research, and active learning exercises, BUILT fosters skills critical for future professionals as we move toward a more collaborative and sustainable future.

\section{BUILT FACULTY FELLOWS}

Faculty that wish to receive assistance with course development apply to become BUILT Faculty Fellows. During application, faculty propose the initial concept of an active learning exercise, specifying intended audience and course the exercise is to be located within. Once the application is approved, BUILT Faculty Fellows receive a stipend of $(\$ 5,000)$ and BUILT resources to develop and deploy the active learning exercise.

As a BUILT Faculty Fellow, faculty receive all BUILT resources including staff and purchasing tools appropriate for the intended audience and subject matter. BUILT staff works with the BUILT Faculty Fellow to refine the active learning exercise in such a way that it utilizes hands-on research to reinforce course material and introduce building science education. Once the active learning exercise is clearly defined, BUILT takes the lead on selecting appropriate tools, developing handouts and worksheets with regular feedback from the BUILT Faculty Fellow. During the deployment of the exercise, BUILT staff is available for tool training, check-out and in-class tutorials including introductory lectures on building science.

Through BUILT Faculty Fellows, BUILT reaches a diverse range of students in a wide spectrum of courses. To date, BUILT has active learning exercises in three large, lecture based courses: (1) an introductory (freshman) level course on environmental design open to all majors, (2) the second course in the architectural history sequence typically taken second year (sophomore), and (3) the third course in the architectural history sequence typically taken second year (sophomore). Additionally, BUILT resources are utilized by three seminar courses: (1) a sophomore-level seminar focused on introductory building science principles and research methods with an interdisciplinary group of architecture, urban planning, and engineering students, (2) a senior-level architecture seminar focused on the application of building science to multi-family housing with an emphasis on climate-responsive design, contemporary wood structures and enclosure systems, and (3) a senior-level mechanical engineering course on air quality. The overarching goal of BUILT is to create a scaffold of undergraduate building science research experiences throughout all levels of the curriculum to develop skills and knowledge that will allow these students to conduct research in practice as well as advance much further in the RBDI supported graduate-level seminars to benefit of firms and the profession at large.

\section{RESULTS OF BUILT}

Since BUILT's inception, student exposure to building science research opportunities has more than tripled (figure 5). Approximately 400 students will have participated in BUILT supported active learning exercises by end of spring term 2017, and approximately 40 undergraduate students will utilize BUILT resources in seminars dedicated to building science education. When students that participate in the RBDI is added to undergraduates exposed to building science and research-based design through BUILT, the total number of students exposed to architectural research is anticipated to be over 460 on an annual basis in the coming years. 


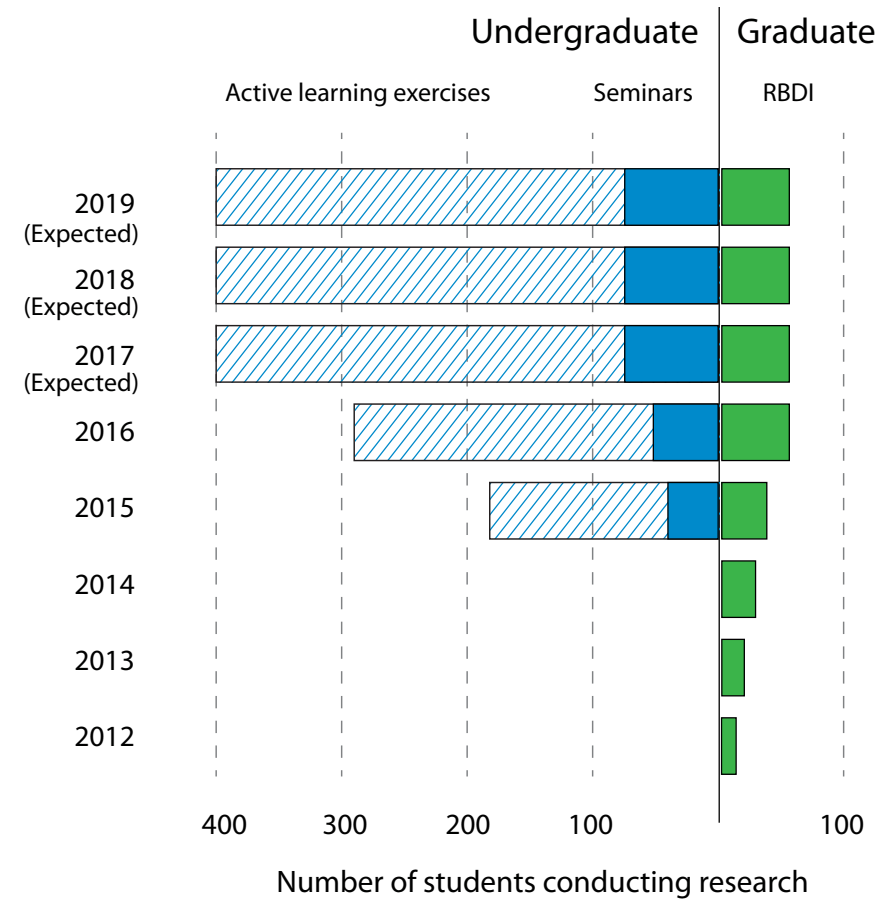

Figure 5: Quantity and methods for student-led research

\section{OUTCOMES OF BUILT}

BUILT expands efforts of the RBDI goals for students to collaborate, work in interdisciplinary groups, and perform student-led building science research by providing research opportunities to students earlier in their education in order to strengthen their building science knowledge and research skills. All aspects of BUILT have been successful so far, with particular success in active learning exercises engendered through partnerships with BUILT Faculty Fellows.

BUILT is an in-house resource for students and reinforces its support by hosting events such as the most recent RBDI symposium. In addition, the expanded curriculum supported by BUILT positively impacts the RBDI. As mentioned, not only are students more prepared to conduct quality research by the time they enroll in the RBDI courses in graduate school, but research conducted at the undergraduate level has positively influenced local firms to join the RBDI.

The most surprising outcome of BUILT is the impact BUILT has had on courses not directly involved with BUILT. Students with previous experience participating in a BUILT active learning exercise or enrolled in a dedicated course return to BUILT seeking tools and advice to solve problems in other coursework - specifically in architectural design studios. These students most frequently come in the beginning of studio, but have been known to come around midterm and pre-finals with last minute questions.

While the number of students conducting building science research has expanded, interdisciplinary groups continue to be difficult to implement. Engineering continues to be under-represented in courses and BUILT related activities. Additionally, while exposure has increased, the number of students specifically studying building science has not. As such, drawbacks in interdisciplinary group work and lack of students with a special interest in green buildings hinder the progress of translational research and sustainable education at Portland State University.

\section{GREEN BUILDING SCHOLARS PROGRAM}

To increase interdisciplinary, research-based design opportunities for students studying green buildings, Professor Griffin along with other faculty from Architecture, Civil Engineering and Mechanical Engineering received a grant of $\$ 630,978$ from the National Science Foundation's Scholarships in Science, Technology, Engineering, and Mathematics (S-STEM) program. The program focuses on increasing student diversity in STEM disciplines through a combination of scholarships, curricular and co-curricular activities that support recruitment, retention, student success, and graduation. At PSU, the grant funds the Green Building Scholars (GBS) program that provides scholarships to increase the number of architecture and engineering students studying building science in interdisciplinary coursework over a period of five years. The grant enabled new educational opportunities focused on reducing the environmental impact of buildings. Three competitive scholarship tracks - (1) freshmen of all majors, (2) juniors/seniors pursuing a B.S. in Architecture, Civil Engineering and Mechanical Engineering and (3) Master's students in those majors - reach students at different points in their education, aligning with admissions processes. Stepped scholarship amounts in each provide an increasing incentive for students to continue their interdisciplinary study of building science. This program will provide a large incentive for students with a strong foundation in building science and financial need to pursue graduate studies where the bulk of advanced building science courses are taught and research is conducted.

Students that receive the scholarship are known as "Green Building Scholars" and enroll in courses focused on green buildings and building science. In addition, Green Building Scholars get unique extracurricular opportunities including special building tours, small group discussions with upper management of architecture and engineering firms, and field trips to experience iconic green buildings/firms/cities. Scholars also have the opportunity to participate in the mentorship program where upperlevel Scholars are paired with a local professional in order to develop a relationship and ask questions to like-minded individuals in the work-force. In this way, students are exposed to contemporary issues, research and work opportunities pertaining to green buildings.

\section{RESULTS OF GREEN BUILDING SCHOLARS PROGRAM}

Now in year three of five, the GBS program has awarded scholarships to 58 students toward a target of 108 students total by the end of the grant. Of the 15 scholars who have graduated, over half are pursuing an advanced degree (Masters or PhD) and the remainder are all employed in architecture or engineering fields related to green buildings and infrastructure. The demographics of the scholars is far more diverse than the general populations of the three disciplines with women making up $45 \%$ of scholars, and under-represented minorities comprising over $40 \%$ of scholars. Most importantly, the number of architecture and engineering students taking a green building or building science course outside of their major has increased three-fold since the inception of the GBS program. 


\section{OUTCOMES OF GREEN BUILDING SCHOLARS PROGRAM}

As the first NSF S-STEM grant to include architecture students, faculty and coursework, the GBS program can serve as a model for nationally funded STEM education efforts to include architecture. At PSU, the GBS program has been critical in opening a dialog between departments about how to best provide interdisciplinary experiences for students. This has led to certain upper-division architecture electives being counted toward engineering degree requirements and providing paths for architecture students to attain prerequisites to take engineering coursework. One goal of the GBS program is to create a minor and graduate certificate in Sustainable Building Systems to formalize the pathways for students to complete an interdisciplinary course of study around the topic of green buildings.

\section{CONCLUSION}

While it is clear that society must reduce the environmental impact of buildings to mitigate climate change, how to do it is not as straightforward. This paper has outlined three interconnected programs at PSU that strive to not only prepare architecture and engineering students to meet the challenges of creating highperformance, low-impact buildings, but also impact professional practice right now by providing research, expertise and resources to improve projects currently under design that these firms wouldn't otherwise have access to. In order to overcome disciplinary silos and institutional barriers, the four grants received proved to be a significant catalyst in encouraging dialog across disciplines and administrative offices. The grants themselves provided resources in (1) scholarships for a diverse, interdisciplinary cohort of students to study building science, (2) equipment and staffing to support the creation new green building research experiences throughout the architecture curriculum, and (3) staffing to coordinate dozens of research collaborations with practice each year.

It remains unclear if the research-based design efforts detailed here will be successful once funding for the three programs ends in two years. All of the grants were intended to be transformative, one-time opportunities, and it is much harder to find grants to sustain ongoing educational efforts. As mentioned earlier, the authors are in the midst of creating new academic programs to formalize the interdisciplinary coursework and curricular paths that have been established. Fortunately, while the architecture firms did not initially contribute financially to the RBDI for the first three years of the program, all of the participating firms now contribute annually, and there is a goal to increase the number of architecture firms participating to increase funding from practice to offset the loss of grant funding. As practitioners with an existing relationship with the RBDI move from one firm to another, there is an expanded network of people to champion this model for architectural research in more firms.

\section{ACKNOWLEDGMENTS}

This material is based upon work supported by the National Science Foundation under Grant No. 1356679. The authors would like to acknowledge the support of the W.M. Keck Foundation, the Oregon Community Foundation's Van Evera and Janet M. Bailey Fund, NCARB and following architecture firms: BORA Architects, Hacker, SRG Partnership, ZGF Architects, YGH Architecture, and OPSIS Architecture. The authors would also like to acknowledge the contributions of the faculty at PSU including Peter Dusicka, David Sailor, Huafen Hu, Elliott Gall, Raul Cal, Sergio Palleroni, B.D. Wortham-Galvin, and Travis Bell. These efforts would not have been possible without the assistantance of several graduate research assistants including Kalina Vander Poel, Cameron Davis, Ossie Pleasant, Thomas (Tucker) Jones, Reid Weber, Ben Deines, and Matt Sedor.

\section{ENDNOTES}

1. US Department of Energy (DOE). Buildings Energy Data Book, US Department of Energy. 2011. http://www.btscoredatabook.net/ [Accessed October 5, 2016]; Corey Griffin, "Research-based design as translational research between the academy and practice," Proceedings of the Architectural Research Centers Consortium (ARCC) 2015 Conference, Chicago, IL, April 6-9, 2015.

2. Ramesh, T., Prakash, R., Shukla, K.K., (2010). Life cycle energy analysis of buildings: An overview, Energy and Buildings, 42(10): 1592-1600.

3. Mills, E., Bourassa, N., Piette, M. A., Friedman, H., Haasl, T., Powell, T., \& Claridge, D. (2005, May). The cost-effectiveness of commissioning new and existing commercia buildings: Lessons from 224 buildings. In National Conference on Building Commissioning: May (Vol. 4, p. 6).

4. Griffin, C. 2015. "Research-based design as translational research between the academy and practice," Proceedings of the Architectural Research Centers Consortium (ARCC) 2015 Conference, Chicago, IL, April 6-9, 2015.

5. Griffin, C.T., Knowles, C., Theodoropoulos, C., and Allen, J. 2010. Barriers to the implementation of sustainable structural materials in green buildings. In: Cruz $\mathrm{P}$ editor. Structures and Architecture: Proceedings of the 1st International Conference on Structures \& Architecture (ICSA2010). Guimarães, Portugal, 21-23 July 2010. pp. 1315-1323; Klotz, L., Horman, M., Riley, D., and Bechtel, J. 2009. Process Transparency for Sustainable Building Delivery. International Journal of Sustainable Engineering 2 (4): 298; Kibert, Charles J. 2008. Sustainable construction green building design and delivery. Hoboken, N.J.: John Wiley \& Sons

6. Simpson, T. W., Hunter, S. T., Bryant-Arnold, C., Parkinson, M., Barton, R. R., Celento, D. and Messner, J., 2009. Interdisciplinary Graduate Design Programs: Results and Recommendations from a NSF Workshop. 2009 ASME Design Engineering Technical Conferences, San Diego, CA; Little, R. 1999. Educating the Infrastructure Professional: A New Curriculum for a New Discipline. Public Works Management \& Policy 4: 93-99.

7. Hoffman, A. and Rebecca Henn, R. 2008. Overcoming the Social and Psychological Barriers to Green Building. Organization \& Environment, 21: 390-419.

8. King, D. 2010. Engineering a low carbon built environment: The discipline of Building Engineering Physics. London: The Royal Academy of Engineering.

9. The Center for Health Design, About, https://www.healthdesign.org/ certification-outreach/edac/about

10. Griffin, C. 2015. "Research-based design as translational research between the academy and practice," Proceedings of the Architectural Research Centers Consortium (ARCC) 2015 Conference, Chicago, IL, April 6-9, 2015.

11. Ibid.

12. Donfrio, M. 2013. Building Knowledge: A Framework for a Translational Research Culture in Architecture. Proceedings of ARCC 2013, Charlotte, NC, March 20-27, 2013. pp. 12-17.

13. Griffin, C. 2015. "Research-based design as translational research between the academy and practice," Proceedings of the Architectural Research Centers Consortium (ARCC) 2015 Conference, Chicago, IL, April 6-9, 2015.

14. Ewing, R. 2010. Research You Can Use: Translational Research: The Next New Thing. Planning. 76, no. 8: 40 .

15. Donfrio, M. 2013. Building Knowledge: A Framework for a Translational Research Culture in Architecture. Proceedings of ARCC 2013, Charlotte, NC, March 20-27, 2013. pp. 12-17. 